\title{
Measurement of Cardiopulmonary Function in Ventilated Neonates with Respiratory Distress Syndrome Using Rebreathing Methodology
}

\author{
CARL L. BOSE, EDWARD E. LAWSON, ALAN GREENE, WILLIAM MENTZ, AND \\ MITCHELL FRIEDMAN \\ Departments of Pediatrics and Medicine, University of North Carolina and Department of Respiratory Therapy, \\ North Carolina Memorial Hospital, Chapel Hill, North Carolina 27514
}

\begin{abstract}
The feasibility of using a multiple gas rebreathing technique to evaluate cardiopulmonary function in the ventilated neonate was assessed by measuring functional residual capacity, diffusing capacity of lung for carbon monoxide, and effective pulmonary capillary blood flow in 10 neonates with respiratory distress syndrome. Measurements were first made on the level of positive end expiratory pressure (PEEP) selected by the clinicians caring for the infants ("clinical" PEEP, mean of $4.4 \pm 0.3 \mathrm{~cm}$ $\mathrm{H}_{2} \mathrm{O}$ ). To evaluate the effect of PEEP on cardiopulmonary function, PEEP was then changed above (mean of $6.7 \pm$ $0.4 \mathrm{~cm} \mathrm{H}_{2} \mathrm{O}$ ) and below (mean of $1.9 \pm 0.3 \mathrm{~cm} \mathrm{H} \mathrm{H}_{2} \mathrm{O}$ ) this level and measurements were repeated. Mean functional residual capacity on clinical PEEP $(10.8 \pm 1.6 \mathrm{ml} / \mathrm{kg})$ was far below the predicted normal and varied directly with changes in PEEP (mean change of $1.2 \mathrm{ml} / \mathrm{kg} / \mathrm{cm} \mathrm{H}_{2} \mathrm{O}$ ). Diffusing capacity of the lung for carbon monoxide on clinical PEEP was $0.04 \pm 0.01 \mathrm{ml} / \mathrm{min} / \mathrm{mm} \mathrm{Hg} / \mathrm{kg}$ and did not change significantly with changes in PEEP. Mean effective pulmonary capillary blood flow was highest (70 $\mathrm{ml} / \mathrm{min} / \mathrm{kg}$ ) at the lowest level of PEEP. However, the effect of increasing PEEP on effective pulmonary capillary blood flow in individual infants varied. Increasing PEEP increased arterial oxygen tension but did not cause changes in systemic arterial pressure or heart rate. We conclude that infants with respiratory distress syndrome have severe lung injury with decreased functional residual capacity and diffusing capacity of the lung for carbon monoxide, and that lung volume improves with the use of PEEP. Although PEEP has a beneficial effect on arterial oxygenation, it may impair systemic oxygen transport in some infants because of its detrimental effect on cardiac output. This detrimental effect on cardiac output could not be detected by usual clinical monitoring techniques. (Pediatr Res 20: 316-320, 1986)
\end{abstract}

\section{Abbreviations}

RDS, respiratory distress syndrome PEEP, positive end expiratory pressure FRC, functional residual capacity

$\dot{\mathrm{Q}}_{\text {eff, }}$ effective pulmonary capillary blood flow

$\mathrm{D}_{\mathrm{L}} \mathrm{CO}$, diffusing capacity of the lung for carbon monoxide $\mathrm{TcPO}_{2}$, transcutaneous oxygen tension

PAo, mean systemic arterial blood pressure

Reccived July 22. 1985; accepted November 27, 1985.

Address for correspondence and reprints Carl L. Bose, M.D., Department of Pediatrics, University of North Carolina, Chapel Hill, NC 27514.

This work was partially supported by grants HD 00475, HD 13280, and United Cercbral Palsy (R-317-80).
RDS is the most common respiratory illness affecting newborn infants and remains a leading cause of mortality and morbidity (1). The dramatic improvement in survival of infants with RDS in the last decade has resulted primarily from the use of mechanical ventilation. However, mechanical ventilation has many undesirable side effects. These include barotrauma resulting in pulmonary air leaks (2) and alterations in pulmonary blood flow and cardiac output resulting from the use of PEEP (3). Attempts by clinicians to minimize these adverse effects in the ventilated neonate have been compromised by the inability to adequately monitor cardiopulmonary variables, e.g. cardiac output and lung volumes. The small size of these patients and lack of easy vascular access has precluded the use of monitoring techniques commonly used in adult patients (4). Presently, the respiratory management of neonates with RDS, including the selection of various modes of ventilation, is based almost exclusively on blood gas analysis.

A multiple gas rebreathing method, first introduced by Sackner et al. (5), permits rapid, on-line, and easily repeatable measurements of several cardiopulmonary variables including FRC, $\dot{\mathrm{Q}}_{\mathrm{eff}}$, and $\mathrm{D}_{\mathrm{L}} \mathrm{CO}$. This technique has already been shown to be accurate and reproducible in animal studies of lung injury (6) and in adult human studies (7). Recently, we have shown that this technique provides an accurate measurement of cardiopulmonary function in mechanically ventilated piglets, comparable in size to the human neonate, including piglets with oleic-acid induced lung injury ventilated using PEEP (8).

The purpose of this study was to evaluate the feasibility of using this rebreathing methodology to measure cardiopulmonary function in mechanically ventilated human neonates with RDS. In addition, we also utilized the rebreathing technique to investigate the effect of PEEP on cardiopulmonary function.

\section{METHODS}

The study population consisted of 10 infants admitted to the Neonatal Intensive Care Unit at North Carolina Memorial Hospital with severe RDS diagnosed by clinical and radiographic features (9). Informed consent was obtained from the parents prior to the study. At the time of entry into the study, all infants were intubated with uncuffed endotracheal tubes and ventilated with pressure-limited, time-cycled ventilators (BP 200 or Bear Cub, Bear Medical Systems, Inc., Riverside, CA) using intermittent mandatory ventilation and PEEP. The initial ventilator settings had been selected by the clinicians caring for the infants (not members of the investigative team) by criteria based primarily on the results of arterial blood gas analyses. The level of PEEP at the time of enrollment into the study is termed the "clinical" PEEP level. The study population is described in Table 1.

Measurements of cardiopulmonary function were made using 
Table 1. Clinical data and respiratory support at the time of entry into the study

\begin{tabular}{ccccccc}
\hline & $\begin{array}{c}\text { Postnatal } \\
\text { age } \\
\text { (days) }\end{array}$ & Sex & $\begin{array}{c}\text { Wt } \\
(\mathrm{kg})\end{array}$ & $\mathrm{FIO}_{2}$ & $\begin{array}{c}\text { Plinical } \\
\left(\mathrm{cm} \mathrm{H}_{2} \mathrm{O}\right)\end{array}$ & $\begin{array}{c}\text { PEEP† } \\
(\mathrm{cm}\end{array}$ \\
$\left.\mathrm{H}_{2} \mathrm{O}\right)$
\end{tabular}

* Peak airway pressure.

$\dagger$ See text for definition.

a rebreathing technique previously described (8). The rebreathing apparatus consisted of a $50 \mathrm{ml}$ rubber bag-in-bottle and valve (total dead space of two $\mathrm{ml}$ ) originally developed by Gallioto et al. (10). The valve was interposed between the endotracheal tube and the ventilator. On turning the valve the inspiratory gas flow from the ventilator could be rapidly diverted to the bag-in-bottle system allowing the infant to be rebreathed with a mixture of test gases contained in the bag. Between measurements the infant was ventilated directly by the ventilator through the valve. The test gas mixture contained $0.3 \% \mathrm{C}^{18} \mathrm{O}, 0.6 \% \mathrm{C}_{2} \mathrm{H}_{2}, 10 \% \mathrm{He}$, and a percentage of oxygen that was $10 \%$ higher than the inspired oxygen concentration being used prior to the measurements. The balance of the test gas mixture was $\mathrm{N}_{2}$. The rebreathing volume used was 15 to $20 \mathrm{ml} / \mathrm{kg}$. Rebreathing was begun at the end of a normal expiration and continued at a rate of 40 breaths $/ \mathrm{min}$ for $30 \mathrm{~s}$. During rebreathing, gentle pressure was applied externally to the trachea to prevent air leakage. This technique eliminated leaks around the endotracheal tube that could be detected by auscultation and produced a flat helium curve after the point of complete mixing between the lung and the rebreathing bag, suggesting that the system remained closed during the measurement period. The gases were continuously sampled at the airway opening by a mass spectrometer (MGA 1100 , Perkin Elmer Corp., Pomona, CA; sampling rate of $15 \mathrm{ml} / \mathrm{min}$ ). The analog signals from the mass spectrometer were directed to a microcomputer (MINC/11, Digital Equipment Corp., Maynard, MA). The computer calculated the slope of the disappearance curves of $\mathrm{C}^{18} \mathrm{O}$ and $\mathrm{C}_{2} \mathrm{H}_{2}$, correcting for the He dilution, after the point of minimal oscillation of the He tracing (Fig. 1). Data were analyzed for three consecutive breaths after this starting point using the algorithm of Sackner et al. (5). Sampling resulted in a linear loss of volume of gas in the lungs and test gas bag during the measurement period. The magnitude of this loss was approximately 5 to $7 \%$ at the point of data analysis. No correction was made for this loss. Rebreathing measurements were done in triplicate and averaged (6). The total time required to obtain and analyze the data was approximately $1 \mathrm{~min}$. Most infants exhibited some spontaneous respiratory effort during the rebreathing measurements. However, their spontaneous tidal volumes were much smaller than the rebreathing volumes used and therefore did not affect the interpretation of gas disappearance curves.

$\mathrm{TcPO}_{2}, \mathrm{PAo}$, and end-tidal $\mathrm{CO}_{2}$ were also monitored in all infants throughout the experiments.

Rebreathing measurements, $\mathrm{TcPO}_{2}$ and PAo values were initially obtained at the respiratory settings chosen by the clinicians (clinical PEEP, Table 1). PEEP was then either increased or

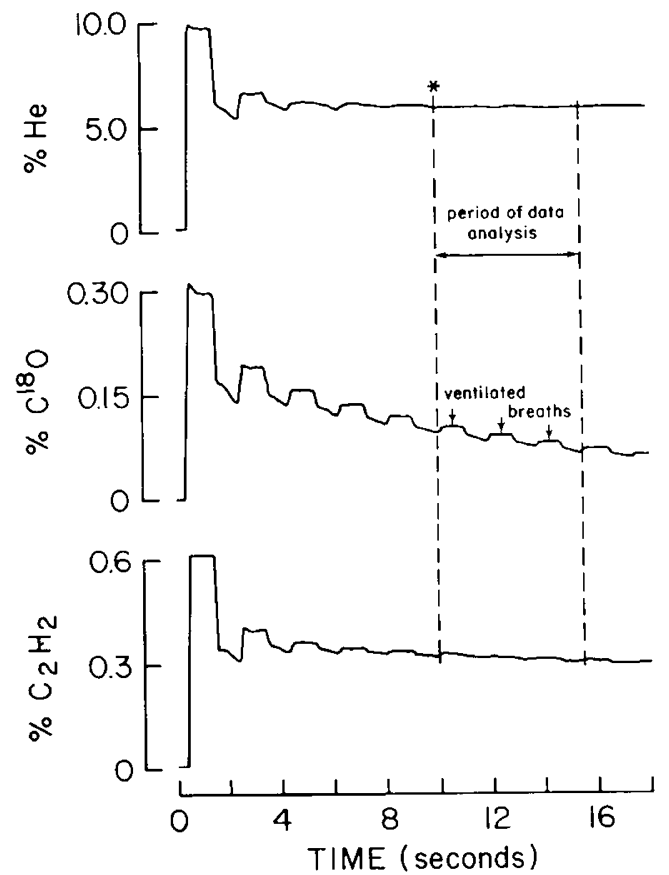

Fig. 1. Changes in gas concentrations, measured at the airway opening, during rebreathing. FRC is calculated from the He curve after the point of equilibration between the lung and the rebreathing bag (indicated by asterisk). $\mathrm{D}_{\mathrm{L}} \mathrm{CO}$ and $\dot{\mathrm{Q}}_{\mathrm{eff}}$ are calculated from the rate of disappearance of $\mathrm{C}^{18} \mathrm{O}$ and $\mathrm{C}_{2} \mathrm{H}_{2}$, respectively, during the first three breaths after the point of He equilibration $\left(^{*}\right)$.

decreased by 2 to $3 \mathrm{~cm} \mathrm{H}_{2} \mathrm{O}$ in a random fashion. After a period of approximately $20 \mathrm{~min}$, all measurements were repeated. PEEP was then changed in the opposite direction 2 to $3 \mathrm{~cm} \mathrm{H}_{2} \mathrm{O}$ above or below the clinical PEEP level and measurements were again repeated after a 20 -min period. Since the rebreathing measurement begins at end-expiration in a closed system, the rebreathing method would not increase end-expiratory pressure.

Six infants were studied at all three levels of PEEP. Because of external constraints, measurements could only be made at two PEEP levels in three additional infants. Another infant developed an erratic breathing pattern on the PEEP level above clinical PEEP, prohibiting the precise determination of the time of endexhalation and accurate timing of the switching of the rebreathing valve. Measurements, therefore, were not made in this infant at the higher PEEP level. One of the infants was studied on 2 consecutive days. The results of measurements made on the 2 nd day in this infant are reported separately.

Statistical analyses were performed using the Student's $t$ test for paired variables to compare values at different levels of PEEP. Values for $p<0.05$ were considered to be significant. All data are expressed as the mean \pm SEM.

\section{RESULTS}

Table 1 describes the study population and the level of ventilatory support at the time of enrollment into the study. The average $\mathrm{FIO}_{2}$ was $0.51 \pm 0.04$ with one infant requiring an $\mathrm{FIO}_{2}$ greater than 0.70 . No patient was ventilated at a peak airway pressure greater than $28 \mathrm{~cm} \mathrm{H}_{2} \mathrm{O}$ (average peak airway pressure of $23 \mathrm{~cm} \mathrm{H}_{2} \mathrm{O}$ ). The average level of clinical PEEP was $4.4 \pm 0.3$ $\mathrm{cm} \mathrm{H}_{2} \mathrm{O}$ (range 3 to $5 \mathrm{~cm} \mathrm{H}_{2} \mathrm{O}$ ).

There appeared to be no adverse effects of making repeated rebreathing measurements in these infants. No decreases in $\mathrm{T}_{\mathrm{C}} \mathrm{PO}_{2}$ occurred during the $30-\mathrm{s}$ measurement periods. In fact, transient small increases in $\mathrm{TcPO}_{2}$ were often observed during the rebreathing period due to the higher concentration of oxygen in the test gas mixture compared to that being delivered by the 
ventilator. End-tidal $\mathrm{CO}_{2}$ rose linearly as a function of time during the 30 -s rebreathing period, due to the fact that the patient was rebreathing in a closed system, but rapidly returned to baseline levels within the first few breaths after the valve was returned to the ventilator mode position. No changes in heart rate, $\mathrm{PAo}$, or airway pressure were observed during or between individual measurements. We have performed over 100 rebreathing measurements in neonates with RDS and have encountered no adverse clinical complications including evidence of barotrauma, changes in systemic arterial pressure, or impairment of oxygenation.

Values for rebreathing variables, $\mathrm{TcPO}_{2}$ and $\mathrm{PAo}$ obtained at the initial clinical PEEP levels and the effects of changing the levels of PEEP are shown in Table 2. Data for $\mathrm{TCPO}_{2}$ and PAo were obtained just prior to each rebreathing measurement. The average $\mathrm{TcPO}_{2}$ at the clinical level of PEEP was $92 \mathrm{~mm} \mathrm{Hg}$. Decreasing PEEP from the clinical level (average of $2.5 \mathrm{~cm} \mathrm{H}_{2} \mathrm{O}$ ) resulted in a significant decrement in $\mathrm{TcPO}_{2}$ (mean decrease of $24 \%$ ). Increasing PEEP above the clinical PEEP level (average of $2.3 \mathrm{~cm} \mathrm{H}_{2} \mathrm{O}$ ) resulted in a numerically higher $\mathrm{TcPO}_{2}$ (average increase of $13 \%$ ) but this increase was not significant. No significant changes in PAo or heart rate occurred when the PEEP level was either increased or decreased (data not shown).

At the clinical level of PEEP, the average value for FRC was $10.8 \mathrm{ml} / \mathrm{kg}$, for $\mathrm{D}_{\mathrm{L}} \mathrm{CO}$ was $0.04 \mathrm{ml} / \mathrm{min} / \mathrm{mm} \mathrm{Hg} / \mathrm{kg}$, and for $\dot{\mathrm{Q}}_{\mathrm{eff}}$ was $62 \mathrm{ml} / \mathrm{min} / \mathrm{kg}$. Increasing the level of PEEP resulted in a significant rise in FRC (mean increase of $37 \%$ ). Lowering the level of PEEP caused a significant decrease in FRC (mean decrease of $34 \%$ ). There was no effect of changes in PEEP in $\mathrm{D}_{\mathrm{L}} \mathrm{CO}$. However, $\mathrm{D}_{\mathrm{L}} \mathrm{CO}$ per unit lung volume decreased with increasing levels of PEEP.

The effect of PEEP on $\dot{Q}_{\mathrm{cf}}$ varied. $\dot{\mathrm{Q}}_{\mathrm{eff}}$ was significantly the highest at the lowest level of PEEP (mean of $70 \mathrm{ml} / \mathrm{min} / \mathrm{kg}$ ). The values for $\dot{\mathrm{Q}}_{\mathrm{efr}}$ at the clinical PEEP level averaged $77 \%$ of the values at the lower level of PEEP. However, only six of nine infants had an increase in $\dot{Q}_{\mathrm{eff}}$ of (average of $44 \%$ ) when PEEP was dropped below clinical PEEP. There was no change in one infant and a decrease of $26 \%$ in $\dot{Q}_{\text {eff }}$ in the other two infants. Mean $\dot{Q}_{\text {eff }}$ did not change significantly when PEEP was elevated above the clinical PEEP level. Only one of seven infants studied had a decrement in $\dot{Q}_{\text {eff }}$ when PEEP was raised above clinical PEEP.

There appeared to be a relationship between the changes in $\dot{\mathrm{Q}}_{\mathrm{eff}}$ and FRC. $\dot{\mathrm{Q}}_{\mathrm{eff}}$ increased (average of 33\%) when PEEP was elevated above the clinical level in three infants. These infants had extremely low FRC values (average of $6.3 \mathrm{ml} / \mathrm{kg}$ ) at the clinical PEEP level. One additional infant with a similar FRC $(5.3 \mathrm{ml} / \mathrm{kg})$ had no change in $\dot{\mathrm{Q}}_{\text {eff }}$ when PEEP was increased. In the remaining three infants studied at the highest PEEP level (average FRC of $16.8 \mathrm{ml} / \mathrm{kg}$ on clinical PEEP), $\dot{Q}_{\text {eff }}$ either decreased or remained unchanged when PEEP was increased above the clinical level. Changes in $\dot{\mathrm{Q}}_{\mathrm{eff}}$ at any PEEP level were not associated with changes in either heart rate or systemic blood pressure.

Patient 7 was studied serially on the 1 st and 2 nd days of life. Between the study days, there was obvious clinical improvement as evidenced by an improvement in oxygenation (decrease in $\mathrm{FIO}_{2}$ from 0.71 to 0.65 and increase in $\mathrm{PaO}_{2} / \mathrm{FIO}_{2}$ ratio from 116 to 155 ) on a lower clinical PEEP level $\left(5\right.$ to $\left.4 \mathrm{~cm} \mathrm{H}_{2} \mathrm{O}\right)$. This clinical improvement was corroborated by rebreathing measurements with an increase in FRC ( 7.6 to $13.6 \mathrm{ml} / \mathrm{kg}$ ) and $\mathrm{D}_{\mathrm{L}} \mathrm{CO}$ $(.02$ to $.03 \mathrm{ml} / \mathrm{min} / \mathrm{mm} \mathrm{Hg} / \mathrm{kg}$ ) on the clinical PEEP level from the first day compared to the 2 nd study day (Table 3 ). No change in $\dot{Q}_{\text {efr }}$ at the clinical PEEP level occurred between study days. Increasing PEEP above the clinical level 5 to $7 \mathrm{~cm} \mathrm{H}_{2} \mathrm{O}$ caused an increase in $\dot{Q}_{\text {eff }}$ of $62 \%$ on the 1 st study day. A similar increase in PEEP on the 2nd day caused a decrease in $\dot{Q}_{\text {eff }}$ of $19 \%$.

The average coefficient of variation for repeated measurements in all subjects at all PEEP levels were FRC $14 \pm 2 \%, \dot{Q}_{\text {eff }} 18 \pm$ $2 \%$, and $\mathrm{D}_{\mathrm{L}} \mathrm{CO} 23 \pm 3 \%$. Rebreathing methodology has also been used to measure lung water (11). However, because of the diffuse heterogeneous nature of the lung injury in these infants, highly reproducible measurements of lung water could not be obtained and are therefore not reported.

Table 2. Cardiopulmonary function variables at different PEEP levels*

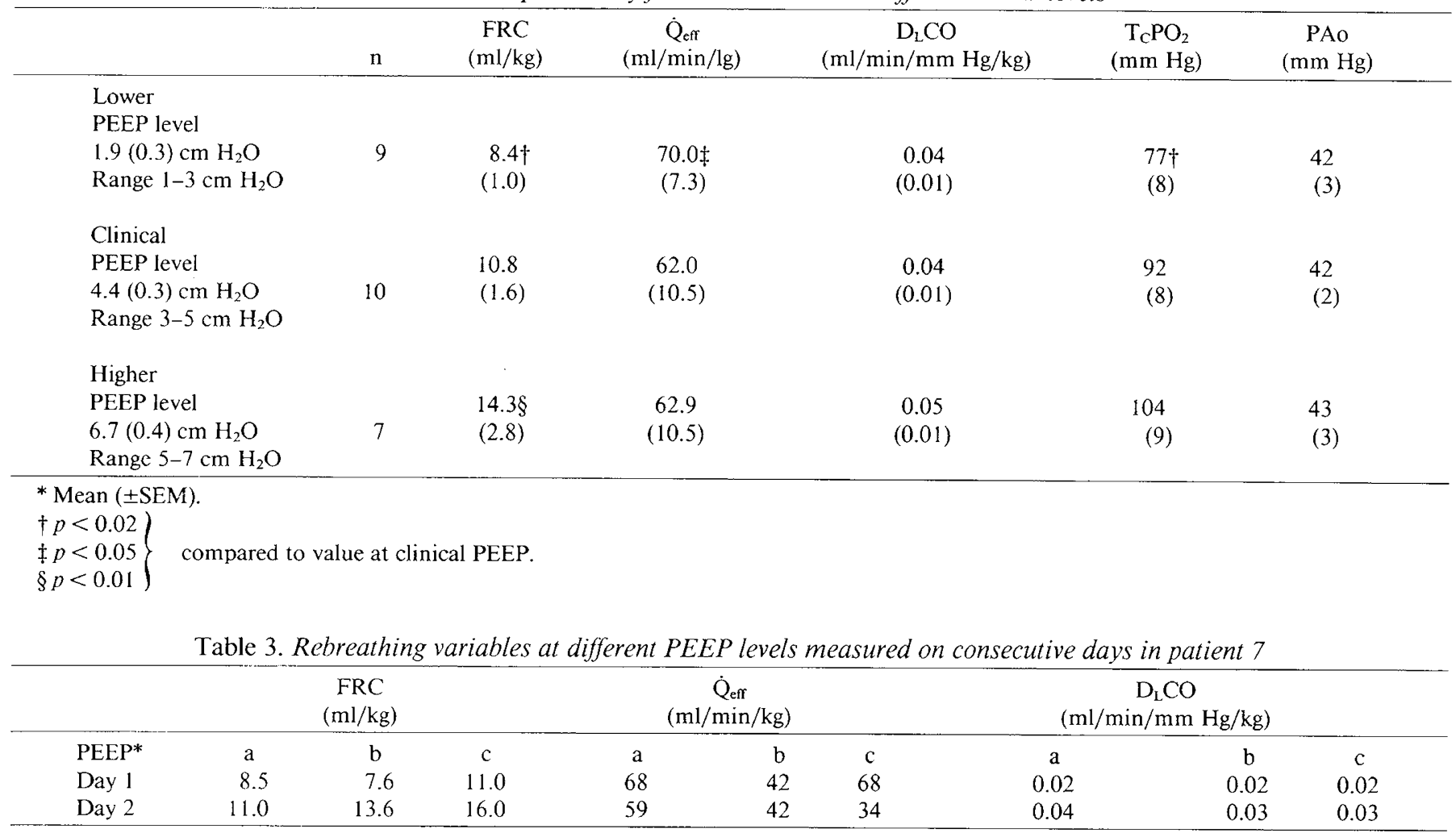

* PEEP levels: $\mathrm{a}=$ level below "clinical " level; $\mathrm{b}=$ "clinical" level; $\mathrm{c}=$ level above "clinical" level. 


\section{DISCUSSION}

Multiple gas rebreathing methodology is an established technique for assessing cardiopulmonary function in large animals (6) and adult humans (7). This technique has recently been adapted for use in small laboratory animals comparable in size to premature human neonates (8). Utilizing an extremely low dead space valve and a bag-in-bottle system that allows for repetitive measurements, we have demonstrated that the rebreathing method is a rapid, repeatable, and safe bedside technique for measuring FRC, $\dot{\mathrm{Q}}_{\mathrm{eff}}$, and $\mathrm{D}_{\mathrm{L}} \mathrm{CO}$ in ventilated neonates. We have not observed complications of making repetitive measurements in neonates with RDS. Although a brief period of minimal $\mathrm{CO}_{2}$ retention (end-tidal $\mathrm{CO}_{2}$ levels $<10 \%$ for less than $5 \mathrm{~s}$ ) occurs during measurements, no significant changes in oxygenation occur. Measurements take less than $30 \mathrm{~s}$ and results are immediately available.

This technique offers advantages over other methods of measuring cardiopulmonary function (e.g. cardiac output and diffusing capacity) in small infants. The measurement of $\dot{\mathrm{Q}}_{\text {eff }}$ provides a relatively noninvasive estimation of cardiac output $(5,8$, 11). This measurement can be made without the use of vascular catheters, which may be technically difficult to place and potentially hazardous in premature neonates. In contrast to the measurement of $\mathrm{D}_{\mathrm{L}} \mathrm{CO}$ by single breath methods which would require repeated disconnections of the patient from the ventilator, the rebreathing system does not require separation of the infant from the ventilator.

Measurement of $\dot{Q}_{\mathrm{eff}}$ by rebreathing has been demonstrated, by comparison to dye and thermal dilution techniques, to be a very reliable estimate of cardiac output in a variety of laboratory models, including normal piglets (8), dogs (11), and human adults (12). Measurement of cardiac output by this method assumes homogeneous ventilation to volume, ventilation to perfusion, and perfusion to volume distributions. Certainly nonuniform distribution of ventilation and perfusion would be expected in the neonates with RDS studied. However, accurate estimates of various rebreathing parameters have also been demonstrated in laboratory models of abnormal ventilation to perfusion distribution within the lung, similar to those which might be expected in infants with $\operatorname{RDS}(8,11)$. Friedman et al. (11) observed no effect of profound alterations in perfusion following unilateral pulmonary artery occlusion on the measurement of $\dot{Q}_{\text {eff }}$ compared with total cardiac output measured by dye dilution in ventilated dogs (11). Similarly, maldistribution of ventilation does not appear to effect the accuracy of $\dot{Q}_{\mathrm{efr}}$ as an estimate of total cardiac output (13). Rebreathing methodology measures pulmonary capillary blood flow $\left(\dot{Q}_{\text {eff }}\right)$ only to ventilated regions of the lung. Blood flow to nonventilated areas of lung is not included in the measurement, resulting in underestimation of total cardiac output when significant right to left shunting occurs. For example, Friedman et al. (11) demonstrated a $50 \%$ reduction in the measurement of $\dot{Q}_{\text {eff }}$ following unilateral bronchial occlusion, but no change in total cardiac output measured by dye dilution. Therefore, $\dot{Q}_{\mathrm{eff}}$ cannot be assumed to be equivalent to total cardiac output in infants with right to left shunting, including those with RDS. However, changes in $\dot{Q}_{\text {eff }}$ will parallel changes in total cardiac output, if significant concurrent changes in right to left shunting do not occur. Similarly, changes in systemic oxygen transport, the product of total cardiac output and arterial oxygen content, can be accurately predicted if the shunt fraction remains constant.

The values obtained for FRC at the clinical PEEP level demonstrate the marked reduction in lung volume associated with RDS, even in infants treated with modest levels of PEEP. FRC, measured at the clinical PEEP level, was compared to FRC measurements reported by Hanson and Shinozaki (14) using breath by breath analysis of nitrogen washout. These authors found that the mean FRC was $17 \pm 2 \mathrm{ml} / \mathrm{kg}$ in a population of healthy, nonventilated infants. This study is used for comparison because it is the largest study of FRC in newborn infants. Although, their study group included predominantly term infants, extrapolation of their values to preterm infants appears reasonable since Kraus and Auld (15) have reported no differences in FRC values between term and preterm infants when the values are adjusted for body weight. Other investigators have reported higher FRC values than Hanson and Shinozaki (16). Regardless of the study used for comparison however, our finding that mean FRC on clinical PEEP was $10.8 \pm 1.6 \mathrm{ml} / \mathrm{kg}$ clearly shows that FRC in infants with RDS is far below predicted normal. Further evidence for the severity of lung injury in these infants are the values obtained for $\mathrm{D}_{\mathrm{L}} \mathrm{CO}$ which were approximately $10 \%$ of those predicted from previous studies of normal animals of similar size (8).

There was a direct correlation between the level of PEEP and FRC. FRC increased approximately $1.2 \mathrm{ml} / \mathrm{kg}$ for every $1 \mathrm{~cm}$ $\mathrm{H}_{2} \mathrm{O}$ increase in PEEP. This increase in FRC with increasing levels of PEEP is similar to the increase observed in our previous study of piglets with diffuse lung injury (8). Every infant in the study had an increase in FRC with each increase in PEEP level, but only three of seven infants tested reached predicted normal lung volumes $(17 \pm 2 \mathrm{ml} / \mathrm{kg})$ on the highest level of PEEP. This observation further corroborates the extent of the lung injury in these patients and emphasizes the need to directly measure lung volumes if the goal of ventilator therapy is to normalize FRC.

An adverse effect of PEEP on cardiac output might have been predicted from previous observations made in both adult (17) and neonatal (8) animals and adult humans (7). However, the effect of PEEP on $\dot{Q}_{\text {eff }}$ in our study infants was variable. Six of nine infants had an increase in $\dot{Q}_{\text {eff }}$ when PEEP was decreased from the clinical PEEP to the lowest level but only one of seven had a decrement in $\dot{Q}_{\text {eff }}$ when PEEP was raised above the clinical level. The complex interaction between PEEP and $\dot{Q}_{\mathrm{eff}}$ is further illustrated by the effect of varying levels of PEEP on consecutive days in patient 7 . On the 1st study day, increasing PEEP from 3 to $5 \mathrm{~cm} \mathrm{H}_{2} \mathrm{O}$ resulted in a decrease in Q $\dot{Q}_{\text {eff, while }}$ increasing PEEP from 5 to $7 \mathrm{~cm} \mathrm{H}_{2} \mathrm{O}$ caused an increase in $\dot{\mathrm{Q}}_{\text {eff. }}$. On the 1 st day, the infant's clinical disease was severe with FRC values of only $11 \mathrm{ml} / \mathrm{kg}$ at the highest level of PEEP. However, on the 2nd study day when the infant's disease had improved, increasing PEEP at each level resulted in a decrement in $\dot{Q}_{\text {eff. }}$ At each higher level of PEEP on the 2nd day, a decrement in $\mathrm{D}_{\mathrm{L}} \mathrm{CO}$ per unit lung volume was also observed suggesting that increasing PEEP increased FRC as a result of alveolar overdistention rather than recruitment of atelectatic lung. This apparent relationship between the severity of disease and the effect of PEEP on $\dot{\mathrm{Q}}_{\mathrm{err}}$ is also suggested by the observation that infants with the lowest FRC on clinical PEEP tended to experience an increase in $\dot{Q}_{\mathrm{cff}}$ as PEEP was increased above the clinical level. However, the small number of infants studied and the lack of a uniform response to changes in PEEP preclude drawing any definitive conclusions.

The need to assess cardiopulmonary function in ventilated infants with RDS, e.g. using rebreathing methodology, is exemplified by the heterogeneity of cardiopulmonary function found in the present study population and the variability of changes in $\dot{\mathrm{Q}}_{\text {eff }}$ in response to changes in PEEP. Although FRC systematically rose as PEEP was increased, the effect of elevated PEEP on cardiac output and systemic oxygen transport varied. Increased PEEP often resulted in decreased $\dot{Q}_{\text {eff }}$ and improved blood oxygenation (suggesting a decrease in the shunt fraction). These findings suggest that PEEP may impair cardiac output, and despite an improvement in arterial oxygenation may result in a net decrease in systemic oxygen transport. In the present study, decrements in cardiac outputs due to increasing PEEP were not detected by standard clinical monitoring techniques. For example, heart rate and mean systemic blood pressure remained constant with manipulation of PEEP. It is possible that more subtle changes in clinical parameters not evaluated in this study, such as decreases in pulse pressure, might parallel the observed 
decrements in cardiac output. Similarly, decrements in cardiac output during a period of observation longer than in the current study may result in the development of metabolic acidosis or decreased urine production. However, significant decrements in $\dot{Q}_{\mathrm{cfr}}$ and total cardiac output with increasing levels of PEEP, resulting in decrements in systemic oxygen transport, may be immediately detectable only by the use of the rebreathing methodology.

We conclude that the multiple gas rebreathing technique provides a rapid and safe method for assessing cardiopulmonary function in the ventilated newborn infant. With this technique, effects of various mechanical ventilator modes, e.g. PEEP, can be serially evaluated which may not be as easily or accurately assessed by other monitoring techniques. Furthermore, commonly used levels of PEEP may cause clinically inapparent compromise in cardiac output. Measurement of cardiopulmonary function by rebreathing methodology may assist the clinician in providing optimal tissue oxygenation at the lowest possible levels of PEEP.

Acknowledgments. The authors thank Sharon Bowers and Deborah Jones for their assistance in manuscript preparation.

\section{REFERENCES}

1. Horwood SP. Boyle MH. Torrance GW. Sinclair JC 1982 Mortality and morbidity of 500 to 1.499 -gram birth weight infants liveborn to residents of a defined geographic region before and after neonatal intensive care. Pediatrics 69:613-620

2. Ogata ES, Gregory GA, Kitterman GA, Phibbs RH, Tooley WH 1976 Pneumothorax in the respiratory distress syndrome: incidence and effect on vital signs, blood gases, and $\mathrm{pH}$. Pediatrics 58:177-183

3. Jardin F, Farcot J-C, Boisante L, Curien N, Margairaz A, Bourdarias J-P 1981
Influence of positive end-expiratory pressure on left ventricular performance. N Engl J Med 304:387-392

4. Wiedemann HP, Matihay MA, Matihay RA 1984 Cardiovascular-pulmonary monitoring in the intensive care unit (part I). Chest 85:537-549

5. Sackner MA, Greenelitch E, Heiman MS, Epstein S, Alkins N 1975 Diffusing capacity, membrane diffusing capacity, capillary blood volume, pulmonary tissue volume, and cardiac output measured by a rebreathing technique. Am Rev Respir Dis 111:157-165

6. Friedman M, Kaufman SH, Wilkins SA, Jr 1980 Analysis of rebreathing measurements of pulmonary tissue volume in pulmonary edema. J Appl Physiol 48:66-71

7. Cassidy SS, Eschenbacher WL, Robertson $\mathrm{CH}$, Nixon JV, Blomqvist G, Johnson RL, Jr 1979 Cardiovascular effects of positive-pressure ventilation in normal subjects. J Appl Physiol 47:453-461

8. Mentz WM, Lawson EE, Friedman M 1984 Measurement of cardiopulmonary function by rebreathing methodology in piglets. Pediatr Res 18:1167-1172

9. Farrell PM, Avery ME 1975 Hyaline membrane disease. Am Rev Respir Dis 11 1:657-688

10. Gallioto FM, Brudno DS, Rivera O, Howard RP 1984 Use of the rebreathing method in the differential diagnosis of congenital heart disease and persistent fetal circulation. Am J Cardiol 54:1305-1309

11. Friedman M, Wilkins SA, Jr, Rothfeld AF, Bromberg PA 1984 Effect of ventilation and perfusion imbalance on inert gas rebreathing variables. $J$ Appl Physiol 56:364-369

12. Triebwasser JH, Johnson RL, Burpo RP, Campbell JC, Reardon WC, Blomqvist CG 1977 Noninvasive determination of cardiac output by a modified acetylene rebreathing procedure utilizing mass spectrometer measurement. Aviat Space Environ Med 48:203-209

13. Reinhart ME, Hughe JR, Kung M, Abraham WM, Ahmed T, Eyre P, Wanner A 1979 Determination of pulmonary blood flow by the rebreathing technique in airflow obstruction. Am Rev Respir Dis 120:533-540

14. Hanson JS, Shinozaki T 1970 Hybrid computer studies of ventilatory distribution and lung volume. I. Normal newborn infants. Pediatrics 46:900-914

15. Krauss AN, Auld PAM 1971 Pulmonary gas trapping in premature infants. Pediatr Res 5:10-16

16. Klaus M, Tooley WH, Weaver KH, Clements JA 1962 Lung volume in the newborn infant. Pediatrics 30:111-116

17. Cassidy SS, Robertson CH, Pierce AK, Johnson RL, Jr 1978 Cardiovascular effects of positive end-expiratory pressure in dogs. J Appl Physiol 44:743750 